\title{
Extent and causes of increased domestic violence during the COVID-19 pandemic: community health worker perspectives from Kenya, Bangladesh, and Haiti
}

\author{
Ann Gottert ${ }^{1}$ (, Tim Abuya ${ }^{2}$, Sharif Hossain ${ }^{3}$, Alain Casseus ${ }^{4}$, Charlotte Warren ${ }^{1}$, Pooja Sripad $^{1}$ (1) \\ 1 Population Council, Washington D.C., USA, ${ }^{2}$ Population Council, Nairobi, Kenya, ${ }^{3}$ Population Council, Dhaka, Bangladesh, ${ }^{4}$ Zanmi Lasante/Partners \\ in Health, Port-Au-Prince, Haiti \\ Keywords: haiti, bangladesh, kenya, violence against children, gender-based violence, intimate partner violence \\ https://doi.org/10.29392/001c.24944
}

\section{Journal of Global Health Reports}

Vol. 5, 2021

\begin{abstract}
Background
Emerging data, media reports, and anecdotal evidence suggest that domestic violence (DV) has increased during the COVID-19 pandemic. However, more detailed data are needed on the magnitude, forms, and causes of DV during COVID-19 in different contexts worldwide. We sought to contribute such evidence from the perspective of community health workers (CHWs) in low-middle income countries in three different regions of the world.
\end{abstract}

\section{Methods}

We conducted phone surveys with female and male CHWs from September-December 2020 in Kenya $(n=1,385)$, Bangladesh $(n=370)$, and Haiti $(n=261)$. Descriptive and selected bivariate analyses were performed.

\section{Results}

In total, 56\%, 32\% and $12 \%$ perceived increased DV in their communities during COVID-19 in Kenya, Bangladesh and Haiti, respectively. This included violence against both intimate partners and children. Key reasons reported for DV increases were increased stress/tension due to loss of employment/income (>80\%) and children being home/misbehaving ( $>50 \%$ ). In Kenya CHWs also cited partners spending more time together (59\%), increased alcohol/substance use (38\%), and conflict over childcare/ housework responsibilities (33\%). In bivariate analyses, in Kenya and Bangladesh, reporting a greater number of reasons for increased DV was associated with reporting co-occurring violence against both intimate partners and children (vs. just partners; $P<0.001)$.

\section{Conclusions}

Over half of CHWs in Kenya and one-third in Bangladesh perceived increased DV during COVID-19, largely due to increased stress/tension related to economic hardship and childcare. Fewer perceived increased DV in Haiti, where lockdowns have been less severe. Preventing and responding to DV must be central to COVID-19 response and recovery plans, and should include meeting families' economic and childcare/schooling needs.

Globally, domestic violence is increasingly seen as a 'shadow pandemic' to COVID-19. ${ }^{1}$ Domesitic Violence (DV) or Abuse, which can be defined as physical, sexual, and/or emotional abuse within the home, predominantly against intimate partners and children, ${ }^{2}$ was an immense pre-pandemic human rights and public health concern. One-third of women worldwide experience violence in their lifetimes, mostly from intimate partners, ${ }^{3}$ and up to one billion children have experienced violence in the past year. ${ }^{4}$ The COVID-19 pandemic and related measures to slow community transmission have potentially exacerbating effects, including economic strain, cramped living conditions, and isolation with abusers - experienced for extended time-periods. ${ }^{1}$ Further, services for victims and survivors of violence are often disrupted or unavailable. ${ }^{1,5}$

DV escalates during times of crisis, including epidemics. ${ }^{6}$ Emerging data, media reports, and anecdotal evidence suggest DV has increased during the COVID-19 pandemic. ${ }^{5,7}$ For instance, $80 \%$ of 28 countries with available data reported increased calls to helplines/hotlines in April, shortly after pandemic-related lockdowns began. ${ }^{5}$ More detailed data on the magnitude, forms, and causes of DV during COVID-19 are needed. Unfortunately, this is made difficult by constraints around carrying out data collection during 
COVID-19, particularly for DV and other sensitive topics given ethical concerns for ensuring participant safety. 5,8

The aim of this study was to provide such evidence via surveys with community health workers (CHWs) in three low- and middle-income countries in different regions of the world: Kenya, Bangladesh, and Haiti. DV has previously been reported as prevalent in each country; Demographic Health Surveys pre-COVID show, for example, that onethird to one-half of women have experienced physical, sexual and/or emotional violence. ${ }^{9}$ Governmental responses to the pandemic in these countries have included stay-athome orders, curfews, travel restrictions and school closures since March 2020. However, the stringency and duration of such policies have varied, for instance, being less stringent in Haiti where COVID-19 case numbers have been comparably low. ${ }^{10}$ CHWs deliver basic healthcare services and health education, conduct surveillance/reporting, and support linkages to facilities across a range of health areas, and are widely respected and trusted by communities. ${ }^{11,12}$ They are also well-positioned to respond in times of crises and - in their often-expanded roles during COVID-1913 can offer new insights into dynamics playing out within households in the communities they serve.

\section{METHODS}

\section{SURVEY PROCEDURES}

The three countries represent a diversity of low- and middle-income countries, and in each country the study was carried out in urban/peri-urban and rural areas. We conducted cross-sectional phone surveys with CHWs from September-December 2020, regarding their work-related roles/ experiences during COVID-19, and their perceptions of the impact of the COVID-19 pandemic/response on their communities (including DV). In Kenya, we took a random sample of 'Community Health Volunteers' across 39 out of the country's 47 counties (those with contact information available from the Ministry of Health). These CHWs are supported by both government and non-governmental organizations (NGOs). In Bangladesh, we conducted proportional sampling of government-supported 'Family Welfare Assistants' and 'Health Assistants' in four districts where the Council conducted recent studies, using our research team's existing contact information. In Haiti, we took a random sample of 'Agents Santé Communautaire Polyvalent' from two Departments who are supported by the Ministry of Health and the NGO Zanmi Lasante, and selected by Zanmi Lasante for this study.

The phone surveys took 30-45 minutes to complete. CHWs used an authentication code and provided informed consent verbally or by SMS. Surveys were administered by experienced interviewers trained on the study protocol, who had at least a bachelor's degree. Interviewers in each country included both women and men about 20-40 years old.

\section{KEY MEASURES}

The extent, nature and causes of DV perceived by CHWs were measured by two questions:
1. Would you say there is more violence in households, during COVID-19? (Response options: No; Yes, violence against wives/intimate partners; Yes, violence against children; Yes, violence against both wives/intimate partners and children).

2. In your view, why is there more violence in households during COVID-19? (for response options see Table 1).

We developed these measures for this study, given lack of such measures in the nascent research around DV during COVID-19. The measures were vetted with in-country study teams before use, and performed well in that there were no refusals to answer, the measures captured substantial variation within and across countries, and few respondents cited 'other' reasons for increased DV (suggesting the reasons for increased DV listed on the survey were relatively comprehensive).

\section{DATA ANALYSES}

We conducted descriptive analyses (yielding frequencies, means and measures of dispersion) for all variables listed in Table 1, as well as selected bivariate analyses, for each country separately. Sample sizes were sufficient to achieve approx. $\pm 3 \%$ precision in Kenya, and $\pm 5 \%$ in Bangladesh and Haiti, around an estimated proportion of 0.5 (most conservative), given $80 \%$ power and alpha of 0.05 (although each sample may not be fully representative of all CHWs, decreasing statistical power). All analyses were conducted in Stata v15 (StataCorp LLC, College Station, Texas).

\section{ETHICS REVIEW}

This study was approved by the Population Council Institutional Review Board (IRB) (protocol number p942) as well as the AMREF Health Africa Ethics and Social Review Committee in Kenya (P836-2020), the Bangladesh Medical Research Council (32228072020), and the Zanmi Lasante IRB in Haiti (ZLIRB 08192020).

\section{RESULTS}

In total, 1,385 CHWs in Kenya, 370 in Bangladesh, and 261 in Haiti completed surveys (see Table 1 for respondent characteristics). Most reported living in the community they work in, have continued their routine work during COVID-19 (for some, including GBV-related services), and provide COVID-19 related services.

Over half (56\%) of CHWs in Kenya, nearly one-third (32\%) in Bangladesh, and 12\% in Haiti, perceived increases in DV in households in their community during COVID-19. In Kenya, CHWs perceived that about half of this violence was directed at wives/intimate partners only, and half to both wives/partners and children; in Bangladesh and Haiti, a majority reported violence directed at both wives/partners and children.Prevailing reasons perceived for increased DV in all three countries include increased economic stressors and increased stress from children being at home. Additional reasons in Kenya and Haiti included partners spending more time together than usual, conflict over childcare/ housework responsibilities, and increased alcohol/substance abuse. Less cited $(<10 \%)$ in each country were 
Table 1. Community health worker characteristics and perceptions of domestic violence during COVID-19

\begin{tabular}{|c|c|c|c|}
\hline & $\begin{array}{c}\text { Kenya } \\
(n=1,385)\end{array}$ & $\begin{array}{l}\text { Bangladesh } \\
(\mathrm{n}=370)\end{array}$ & $\begin{array}{l}\text { Haiti } \\
(n=261)\end{array}$ \\
\hline & \multicolumn{3}{|c|}{$\mathrm{n}(\%)$} \\
\hline \multicolumn{4}{|l|}{ Community health worker characteristics } \\
\hline Age - mean (SD; range) & $\begin{array}{l}44.7 \text { years }(10.6 \\
19-78)\end{array}$ & $\begin{array}{l}44.4 \text { years }(9.5 \\
19-58)\end{array}$ & $\begin{array}{l}46.3 \text { years }(8.0 ; \\
19-65)\end{array}$ \\
\hline Women (\%) & $946(68.3 \%)$ & $298(80.5 \%)$ & $114(43.7 \%)$ \\
\hline \multicolumn{4}{|l|}{ Highest level of education completed } \\
\hline $\begin{array}{r}\text { Secondary } \\
\text { More than secondary }\end{array}$ & $\begin{array}{l}510(36.8 \%) \\
147(10.6 \%)\end{array}$ & $\begin{array}{l}86(23.2 \%) \\
278(75.1 \%)\end{array}$ & $\begin{array}{l}39(14.9 \%) \\
26(10.0 \%)\end{array}$ \\
\hline Urban/peri-urban residence & $354(25.6 \%)$ & $99(26.8 \%)$ & $37(14.2 \%)$ \\
\hline Lives in the community s/he works in & $1,335(96.4 \%)$ & $254(68.7 \%)$ & 240 (92.0\%) \\
\hline \multicolumn{4}{|l|}{ Continued routine work during COVID-19 pandemic ${ }^{a}$} \\
\hline $\begin{array}{r}\text { No } \\
\text { Yes, somewhat } \\
\text { Yes, mostly }\end{array}$ & $\begin{array}{l}35(2.7 \%) \\
502(38.7 \%) \\
758(58.5 \%)\end{array}$ & $\begin{array}{c}1(0.3 \%) \\
45(12.2 \%) \\
323(87.5 \%)\end{array}$ & $\begin{array}{l}13(5.1 \%) \\
180(70.6 \%) \\
62(24.3 \%)\end{array}$ \\
\hline $\begin{array}{l}\text { Provides services related to gender-based violence as part of } \\
\text { routine work }\end{array}$ & $554(40.0 \%)$ & 240 (64.9.\%) & $152(61.0 \%)$ \\
\hline Provides services related to COVID-19c & $1,276(92.1 \%)$ & $140(37.8 \%)$ & $253(96.9 \%)$ \\
\hline \multicolumn{4}{|l|}{ Perceptions of violence during COVID-19 } \\
\hline \multirow[t]{3}{*}{$\begin{array}{l}\text { Perceived increase violence in households during the COVID-19 } \\
\text { pandemic }\end{array}$} & $780(56.3 \%)$ & $118(31.9 \%)$ & $30(11.5 \%)$ \\
\hline & \multicolumn{3}{|c|}{ Among those reporting an increase in violence: } \\
\hline & $(n=780)$ & $(n=118)$ & $(n=30)$ \\
\hline $\begin{array}{l}\text { Victims of increased violence in households } \\
\text { Both wives/intimate partners and children } \\
\text { Wives/intimate partners only } \\
\text { Children only }\end{array}$ & $\begin{array}{c}351(45.0 \%) \\
392(50.3 \%) \\
37(4.7 \%)\end{array}$ & $\begin{array}{l}84(71.2 \%) \\
34(28.8 \%) \\
0(0 \%)\end{array}$ & $\begin{array}{c}7(23.3 \%) \\
14(46.7 \%) \\
9(30.0 \%)\end{array}$ \\
\hline \multicolumn{4}{|l|}{ Perceived reasons for increased violence in households $\underline{d}$} \\
\hline a. Conflict over childcare/housework responsibilities & $259(33.2 \%)$ & $0(0 \%)$ & $11(36.7 \%)$ \\
\hline $\begin{array}{l}\text { b. Partners spending more time together than used to/getting on } \\
\text { each others' nerves }\end{array}$ & 461 (59.1\%) & $23(19.5 \%)$ & $13(43.3 \%)$ \\
\hline $\begin{array}{l}\text { c. Increased stress/tension due child misbehavior/too much time } \\
\text { at home }\end{array}$ & 422 (54.1\%) & $69(58.5 \%)$ & $15(50.0 \%)$ \\
\hline d. Increased stress/tension due to loss of employment/income & 659 (84.5\%) & 109 (92.4\%) & $9(30.0 \%)$ \\
\hline $\begin{array}{l}\text { e. Disagreement or blame around COVID-related risks or } \\
\text { protective measures }\end{array}$ & $71(9.1 \%)$ & $3(2.5 \%)$ & $1(3.3 \%)$ \\
\hline f. Increased alcohol/substance use ${ }^{e}$ & $293(37.6 \%)$ & $0(0 \%)$ & $6(20.0 \%)$ \\
\hline $\begin{array}{l}\text { g. Inability of person/s experiencing violence to leave home to } \\
\text { avoid or report it }\end{array}$ & $73(9.4 \%)$ & $0(0 \%)$ & $0(0 \%)$ \\
\hline h. Other (spontaneous response) & $39(5.0 \%)$ & $0(0 \%)$ & $10(33.3 \%)$ \\
\hline Total number of reasons reported - mean (range) & $1.7(1-3)$ & $2.9(0-7)$ & $2.2(1-4)$ \\
\hline
\end{tabular}

a Based on combining responses to questions about the extent of continuing routine work in the first month after COVID-19 pandemic began, and currently (in month before survey) $\mathrm{b}$ Includes providing documentation, counseling or referral for gender-based violence

${ }^{\mathrm{c}}$ Includes prevention, referral and/or reporting services

${ }^{d}$ Listed in the order in which they occurred on the survey; respondents could select more than one reason.

e This question may be less relevant in Bangladesh where alcohol use is highly restricted and access limited.

COVID-19-related disagreement/blame and the inability of persons experiencing violence to leave home/report it.

In bivariate analyses in Kenya and Bangladesh (where sample size of CHWs reporting increased DV permitted such analyses), reporting a greater number of reasons for increased DV was associated with reporting co-occurring vio- lence against both intimate partners and children (vs. just partners; $P<0.001$ in both countries) (data not shown). Additionally, stressors related to children (i.e., child misbehavior/too much time at home; conflict over childcare/ housework responsibilities), were associated with co-occurring violence (both $\mathrm{P}<0.001$ ), while also reported among 
CHWs perceiving an increase in violence against partners only.

In additional bivariate analyses, CHWs in urban/peri-urban (vs. rural) areas in Kenya were more likely to perceive an increase in DV (63\% vs. 54\%, $P=0.002)$ and "partners spending more time together than used to" as a reason it $(69 \%$ vs. $55 \%, P=0.001$ ). There were no urban/rural differences in Bangladesh.

\section{DISCUSSION}

A large proportion of CHWs perceived increases in DV during COVID-19 as of late 2020 - particularly in Kenya and Bangladesh, in line with other emerging evidence from those countries. ${ }^{14-18}$ Our findings also support emerging research on reasons for increased $\mathrm{DV},{ }^{7}$ which center around increasing stress/tensions due to economic hardship as well as childcare - both closely tied to the stringency and duration of lockdowns. ${ }^{5,14,17,19}$ Notably, in our study CHWs also perceived increased violence due to elevated parental/caregiver stress in managing children at home, which was linked with both violence against partners and especially children.

Following the pattern of perceived increases DV in our study, according to data from the Oxford COVID-19 Government Response Tracker ${ }^{10}$ ) from March-December 2020, 'lockdown style' policies were most strict in Kenya (mean Stringency Index score of 65/100) followed by Bangladesh $(61 / 100)$, then Haiti $(45 / 100)$, largely mirroring the epidemic's scale in those countries. In Haiti, less stringent and shorter-lasting restrictions may have mitigated impacts on increasing DV. Notably, Kenya had both consistent stay-athome requirements and school closures from March-December, unlike Bangladesh or Haiti.

This study has several limitations. Data are descriptive in nature and cannot determine causality of COVID-19 or related restrictions on DV, nor do they directly document DV or trends over time. Our data also do not capture new DV victimization vs. greater frequency/severity, the sex of perpetrators or victims (although women are disproportionately affected by intimate partner violence ${ }^{3}$ ), or perpetration against other household members besides partners and children. Future studies should strive to capture such information. Finally, reports are from the perspective of CHWs rather than household members themselves. However, CHW reports may also be less subject to social desirability bias and may in effect capture experiences of a broader population than individual household members, since each CHW serves hundreds of households.

\section{CONCLUSIONS}

Alongside other emerging evidence, our findings suggest that preventing and responding to DV must be prioritized within governments' COVID-19 response and recovery. ${ }^{1}$ While Kenya, Bangladesh and Haiti each have laws in place regarding domestic violence, these legal provisions are increasingly difficult to implement during the pandemic given competing priorities, reduced budgets, and overburdened health and social services. ${ }^{20}$ Governments and international donors must allocate additional resources and in- clude evidence-based as well as innovative strategies for addressing DV in COVID-19 national response plans. First and foremost, this includes providing clinical services, psychosocial support, and legal assistance for victims of domestic violence. CHWs can play a key role in such efforts, particularly in identifying and referring suspected DV cases during times when victims may have little or no contact with facility-based health and social services. Meeting families' economic and childcare/schooling needs may be particularly critical to preventing DV during COVID-19. It is also important to take into account how restrictive gender norms (e.g., around men as providers, men's control over women, and unequal home and caregiving roles) may intensify stress from such hardships, and to engage men in DV prevention efforts. ${ }^{21}$ Finally, civil society organizations should work to build public awareness about increased risks for DV during COVID-19. The sustained nature of COVIDrelated restrictions, and tendency for surges in DV to be sustained long after disasters are over, ${ }^{6}$ further warrant urgent attention to this 'shadow pandemic'.

\section{ACKNOWLEDGEMENTS}

We thank all study participants and study teams in Kenya, Bangladesh and Haiti. We thank Drs. Ashish Bajracharya, Julie Pulerwitz and Sanyukta Mathur for their advice on the manuscript.

\section{FUNDING}

This manuscript presents original analyses of data collected under the Frontline Health Project, funded by the Bill \& Melinda Gates Foundation. The findings and conclusions contained within are those of the authors and do not necessarily reflect positions or policies of the Bill \& Melinda Gates Foundation.

\section{AUTHORSHIP CONTRIBUTIONS}

AG led the analyses and wrote the manuscript. PS, TM, SH \& AC contributed to the analysis. PS, CW, TA, SH \& AC led the study conceptualization. TA, SH \& AC led study implementation in Kenya, Bangladesh and Haiti. All authors reviewed manuscript drafts and approved the final manuscript.

\section{COMPETING INTERESTS}

The authors have no competing interests to declare.

\section{CORRESPONDENCE TO:}

\author{
Dr. Ann Gottert, PhD, MPH \\ Population Council \\ 4301 Connecticut Ave NW, Suite 280 \\ Washington, D.C. 20008 \\ +1202-904-0234 \\ agottert@popcouncil.org
}

Submitted: May 05, 2021 GMT, Accepted: June 07, 2021 GMT 

mons.org/licenses/by/4.0/legalcode for more information. 


\section{REFERENCES}

1. UN Women. The Shadow Pandemic: Violence Against Women during COVID-19. Published December 29, 2020. https://www.unwomen.org/en/ne ws/in-focus/in-focus-gender-equality-in-covid-19-res ponse/violence-against-women-during-covid-19

2. United Nations. What Is Domestic Abuse? Published May 22, 2021. https://www.un.org/en/coro navirus/what-is-domestic-abuse

3. World Health Organization. Regional estimates of violence against women: Prevalence and health effects of intimate partner violence and non-partner sexual violence. Published online 2013. Accessed December 29, 2020. https://www.who.int/publication s/i/item/9789241564625

4. Hillis S, Mercy J, Amobi A, Kress H. Global prevalence of past-year violence against children: a systematic review and minimum estimates. Pediatrics. 2016;137(3).

5. UN Women. Impact of COVID - 19 on violence against women and girls and service provision: UN Women rapid assessment and findings. Published online 2020.

6. Sety M, James K, Breckenridge J. Understanding the risk of domestic violence during and post natural disasters: Literature review. In: Issues of Gender and Sexual Orientation in Humanitarian Emergencies. Springer; 2014:99-111.

7. Sharma A, Borah SB. Covid-19 and domestic violence: an indirect path to social and economic crisis. Journal of family violence. Published online 2020:1-7.

8. Undie CC, Mathur S, Haberland N, Vieitez I, Pulerwitz J. Opportunities for SGBV data collection in the time of COVID-19: The value of implementation science. Sexual Violence Research Initiative (SVRI) blog. Published 2020. Accessed April 29, 2021. http s://svri.org/blog/opportunities-sgbv-data-collection-t ime-covid-19-value-implementation-science

9. The DHS Program. Demographic and Health Surveys. Published November 10, 2021. https://dhspr ogram.com/Countries/

10. Hale T, Petherick A, Phillips T, Webster S.

Variation in government responses to COVID-19. Blavatnik school of government working paper. 2020;31.
11. Agarwal S, Kirk K, Sripad P, Bellows B, Abuya T, Warren C. Setting the global research agenda for community health systems: literature and consultative review. Human resources for health. 2019;17(1):1-8.

12. Perry HB, Zulliger R, Rogers MM. Community health workers in low-, middle-, and high-income countries: an overview of their history, recent evolution, and current effectiveness. Annual review of public health. 2014;35:399-421.

13. Bhaumik S, Moola S, Tyagi J, Nambiar D, Kakoti M. Community health workers for pandemic response: a rapid evidence synthesis. BMJ Global Health. 2020;5(6):e002769.

14. Hamadani JD, Hasan MI, Baldi AJ, et al. Immediate impact of stay-at-home orders to control COVID-19 transmission on socioeconomic conditions, food insecurity, mental health, and intimate partner violence in Bangladeshi women and their families: an interrupted time series. The Lancet Global Health. 2020;8(11):e1380-e1389.

15. Rayhan I, Akter K. Prevalence and Associated Factors of Intimate Partner Violence (IPV) against Women in Bangladesh amid COVID-19 Pandemic. Published online 2020.

16. Sifat RI. Impact of the COVID-19 pandemic on domestic violence in Bangladesh. Asian journal of psychiatry. Published online 2020.

17. Flowe HD, Rockowitz S, Rockey J, et al. Sexual and Other Forms of Violence During the COVID-19 Pandemic Emergency in Kenya. Published online 2020.

18. Austrian K, Pinchoff J, Tidwell JB, et al. COVID-19 related knowledge, attitudes, practices and needs of households in informal settlements in Nairobi, Kenya. Published online 2020.

19. Population Council. Kenya: COVID-19 Perceptions, Prevention Practices, and Impact: Responses from fourth round of data collection in five Nairobi informal settlements (Kibera, Huruma, Kariobangi, Dandora, and Mathare). Published online 2020. Accessed February 13, 2021. https://www.popco uncil.org/uploads/pdfs/2020PGY_Covid_KenyaKAPSur vey_Round4-Stigma.pdf 
20. UN Women. COVID-19 and Ending Violence Against Women and Girls. Published online 2020. Accessed December 29, 2020. https://www.unwome n.org/-/media/headquarters/attachments/sections/lib rary/publications/2020/issue-brief-covid-19-and-endi ng-violence-against-women-and-girls-en.pdf?la=e $\underline{n} \& v s=5006$
21. Betron M, Gottert A, Pulerwitz J, Shattuck D, Stevanovic-Fenn N. Men and COVID-19: Adding a gender lens. Global Public Health. Published online 2020:1-3. 